\title{
DAYA SAING EKSPOR KAKAO OLAHAN INDONESIA
}

\author{
Dahlia Nauly* , Edmon Daris** dan Iskandar Andi Nuhung**
}

\begin{abstract}
Indonesia is the third largest cocoa producer in the world. Most cocoa is exported out of the country. The government implements regulations that restrict the export of cocoa. The decline in cocoa exports causes a decline in cocoa production. It would require an analysis of competitiveness of processed cocoa on the world market. The study aims to analyze competitiveness of Indonesian processed cocoa on the world market and the competition among countries exporting cocoa on the world market. The method used is Revealed Comparative Advantage (RCA), Trade Specialization Index and Model Almost Ideal Demand System. The study finds that Indonesia has high competitiveness for cocoa paste (the Average Value RCA 1.79), cocoa butter (5.48) and cocoa powder (2.46), while brown Indonesia does not have a competitive edge (0.23). The competitiveness of Indonesian cocoa paste below Ivory Coast (Average Value RCA 276.86), the Netherlands (4.94) and Malaysia (2.46), higher than Germany (1.09). In Indonesia cocoa butter is above France (2.02), but below Ivory Coast (91.67), the Netherlands (9.27) and Malaysia (7.09). While cocoa powder is under the Netherlands (11.49) and Malaysia (5.18), but above Spain (2.26) and Germany (0.74). Trade Specialization Index describes Indonesia at a mature stage. In cocoa butter, Indonesia and Ivory Coast is a net exporter. Meanwhile, cocoa powder of Indonesia, Dutch, Malaysia, Spain, and Germany are at the stage of export expansion. The world market views that cocoa paste of the Netherlands and Indonesia are complementary while cocoa pasta of Germany and Indonesia are mutually substituted, and cocoa butter of Indonesia and the Netherlands are complement. Therefore, Indonesia needs to improve the quality of cocoa paste and powder and still impose import duties that can be processed cocoa to increase the added value.
\end{abstract}

Keywords: Cocoa, Competitiveness, Export

\begin{abstract}
ABSTRAK
Indonesia merupakan penghasil kakao terbesar ketiga di dunia. Sebagian besar kakao diekspor keluar negeri. Maka pemerintah menerapkan peraturan yang membatasi ekspor kakao. Menurunnya ekspor kakao mengakibatkan turunnya produksi kakao. Maka diperlukan analisis tentang daya saing kakao olahan di pasar dunia. Penelitian bertujuan
\end{abstract}


menanalisis daya saing kakao olahan Indonesia di pasar dunia dan persaingan antar negara pengekspor kakao olahan di pasar dunia. Metode yang digunakan adalah Revealed Comparative Advantage (RCA), Indeks Spesialisasi Perdagangan dan Model Almost Ideal Demand System. Dari penelitian diketahui bahwa Indonesia memiliki daya saing tinggi untuk komoditas kakao pasta (Nilai Rata-Rata RCA 1,79), kakao butter $(5,48)$ dan kakao bubuk (2,46), sedangkan cokelat Indonesia belum memiliki daya saing $(0,23)$. Daya saing kakao pasta Indonesia dibawah Pantai Gading (Nilai Rata-Rata RCA 276,86), Belanda $(4,94)$ dan Malaysia (2,46), lebih tinggi dari Jerman (1,09). Dalam kakao butter Indonesia diatas Perancis (2,02), namun dibawah Pantai Gading (91,67), Belanda (9,27) dan Malaysia (7,09). Sedangkan kakao bubuk dibawah Belanda $(11,49)$ dan Malaysia $(5,18)$, tapi diatas Spanyol $(2,26)$ dan Jerman $(0,74)$. Indeks Spesialisasi Perdagangan menjelaskan Indonesia di tahap matang. Pada kakao butter Indonesia dan Pantai Gading merupakan net eksportir. Sedangkan kakao bubuk Indonesia Belanda, Malaysia, Spanyol, dan Jerman berada pada tahap perluasan ekspor. Pasar dunia memandang bahwa kakao pasta Belanda dan Indonesia saling melengkapi sementara kakao pasta Jerman dan Indonesia saling bersubstitusi. Sedangkan kakao butter Indonesia dan Belanda saling berkomplementer. Oleh karena itu Indonesia perlu meningkatkan kualitas kakao pasta dan bubuk.dan tetap memberlakukan bea agar sebagia besar kakao dapat diolah sendiri sehingga dapat menaikan nilai tambah.

Kata Kunci : Kakao, Daya Saing, Ekspor

\section{PENDAHULUAN}

Indonesia merupakan produsen biji kakao terbesar ketiga dunia. Menurut data ICCO (International Cocoa Organization) pada tahun 2011/2012 produksi biji kakao Indonesia sebesar 440 ribu ton sementara Pantai Gading (1.486 ribu ton) dan Ghana (879 ribu ton). Sebagai salah satu negara produsen biji kakao terbesar dunia, sampai awal tahun 2010 sebagian besar produksi biji kakao tersebut diekspor keluar negeri. Hal ini menyebabkan industri pengolahan kakao dalam negeri kekurangan bahan baku. Kemudian pemerintah mengeluarkan Peraturan Menteri Keuangan No
67/PMK.011/2010 yang menetapkan bea keluar bagi biji kakao dan berlaku sejak April 2010. Kebijakan ini bertujuan untuk menjamin ketersediaan bahan baku serta meningkatkan daya saing industri pengolahan dalam negeri.

Penerapan bea keluar tersebut sudah terlihat dampaknya. Berdasarkan data yang diperoleh dari Kementerian Perdagangan RI, pada tahun 2012 hanya 39 persen ekspor kakao Indonesia dalam bentuk biji kakao. Angka ini menurun dibandingkan pada tahun 2008 yang mencapai 69 persen. Data tersebut menunjukkan bahwa kebijakan bea keluar telah mampu menurunkan ekspor 
kakao mentah (berupa biji) dan meningkatkan ekspor kakao olahan. Namun yang perlu diperhatikan juga adalah bahwa semenjak dikeluarkannya kebijakan tersebut total ekspor kakao Indonesia mengalami penurunan. Bahkan penurunan tersebut merupakan penurunan terbesar sepanjang tahun 1967 sampai 2012. Hal ini dikarenakan persentase penurunan ekspor biji kakao lebih besar dibandingkan peningkatan ekspor yang terjadi pada kakao olahan.

Apabila dilihat dari sisi dunia, berdasarkan data tahun 2002/2003 dan 2011/2012 ICCO (2012) memperkirakan konsumsi kakao dunia akan tumbuh sebesar 2,9 persen setiap tahunnya. Sementara ICCO (2013) juga memperkirakan telah terjadi penurunan produksi biji kakao dunia sebesar 5,3 persen (tahun 2011/2012) dan 3,65 persen (tahun 2012/2013). Produksi biji kakao yang menurun dan konsumsi kakao yang meningkat mengakibatkan persaingan dengan sesama produsen kakao olahan dunia semakin meningkat di masa yang akan datang. Dalam menghadapi penurunan ekspor kakao Indonesia dan persaingan dengan sesama produsen kakao olahan dunia diperlukan upaya untuk meningkatkan ekspor kakao olahan. Oleh sebab itu akan dilakukan analisis yang lebih mendalam mengenai daya saing ekspor kakao olahan di pasar dunia. Penelitian ini bertujuan untuk:

(1) Menganalisis daya saing kakao olahan Indonesia di pasar dunia.
(2) Menganalisis posisi persaingan antara negara pengekspor kakao olahan di pasar dunia.

\section{METODE PENELITIAN}

\section{Jenis dan Sumber Data}

Jenis data yang digunakan dalam penelitian ini adalah data sekunder tahunan deret waktu (time series), yaitu tahun 1990 sampai 2012 yang bersumber dari United Nations Commodity Trade Statistics (UN COMTRADE). Adapun sumber-sumber data lainnya diperoleh dari: International Cocoa Organization (ICCO).

\section{Metode Analisis}

\section{Revealed Comparative Advantage (RCA)}

Metode Revealed Comparative Advantage (RCA) digunakan dalam penelitian ini untuk menganalisis daya saing dan keunggulan komparatif kakao olahan Indonesia. Perumusan RCA oleh Balassa dan Bela (1965) adalah sebagai berikut :

$$
R C A=\frac{\frac{X_{i j}}{X_{i}}}{\frac{X_{w j}}{X_{w}}}
$$

$\mathrm{X}_{\mathrm{ij}} \quad=$ nilai ekspor komoditas $\mathrm{j}$ dari negara i

$\mathrm{X}_{\mathrm{i}}=$ nilai ekspor total negara $\mathrm{i}$

$\mathrm{X}_{\mathrm{wj}}=$ nilai ekspor dunia komoditas $\mathrm{j}$

$\mathrm{X}_{\mathrm{w}}=$ nilai total ekspor dunia 
Apabila Nilai RCA $>1$, berarti negara i memiliki keunggulan komparatif (memiliki daya saing) sehingga relatif lebih berspesialisasi di kelompok komoditas yang bersangkutan. Sedangkan Nilai RCA $<1$, berarti negara i tidak memiliki keunggulan komparatif.

\section{Indeks Spesialisasi Perdagangan (ISP)}

ISP ini digunakan untuk menjelaskan posisi Indonesia yang cenderung menjadi negara eksportir atau importir. Nilai indeks ISP berkisar antara -1 (net importir) sampai +1 (net eksportir). Jika nilainya positif diatas 0 sampai 1, maka komoditi tersebut dikatakan mempunyai daya saing yang kuat atau negara tersebut cenderung sebagai eksportir. Sebaliknya daya saingnya rendah atau cenderung sebagai importir jika nilainya negatif (dibawah 0 hingga -1). Apabila indeksnya naik berarti daya saingnya meningkat, demikian pula sebaliknya. Pada tahap pengenalan ISP berkisar antara -1 hingga $-0,5$; tahap substitusi impor antara $-0,4$ dan 0 ; tahap perluasan ekspor antara 0 hingga 0,7 ; tahap matang 0,8-1. Dengan menggunakan perangkat ISP ini dapat diperoleh gambaran mengenai perubahan atau pergeseran keunggulan komparatif untuk setiap produk. Rumus perhitungan ISP adalah:

$$
\begin{aligned}
& \text { ISP }=\frac{(X-M)}{(X+M)} \\
& \mathrm{X}=\text { Ekspor } \\
& \mathrm{M}=\text { Impor }
\end{aligned}
$$

\section{Model Almost Ideal Demand System}

Untuk mengetahui posisi Indonesia diantara negara eksportir lainnya digunakan model Almost Ideal Demand System. Model ini adalah model yang diadopsi dari model yang digunakan oleh Deaton dan Muellbauer. (1980) yang dikembangkan Winters (1983), yaitu sebagai berikut:

$$
S_{i}=\alpha_{i}+\beta_{i} \ln \left(\frac{M}{P^{*}}\right)+\sum_{i=1}^{n} \gamma_{i j} \ln P_{j}+\varepsilon_{t}
$$
$\mathrm{S}_{\mathrm{i}}=$ Pangsa pasar negara pengekspor tertentu dipasar dunia

$$
\begin{array}{ll}
\mathrm{M} & =\text { Total ekspor dunia } \\
\mathrm{P} & =\text { Harga Komoditas } \\
\mathrm{P}^{*} & =\text { Indeks Harga Stone (Stone } \\
& \text { Price Index) } \\
\varepsilon_{\mathrm{i}} & =\text { Error }
\end{array}
$$

Indeks Harga Stone (Stone Price index) didapat dengan menggunakan rumus berikut:

$$
\ln P^{*}=\sum_{i=1}^{n} S_{i, t} \ln P_{i, t}
$$

$$
\begin{aligned}
& \mathrm{S}_{\mathrm{i}, \mathrm{t}}=\text { pangsa pasar negara } \mathrm{i} \\
& \mathrm{P}_{\mathrm{i}, \mathrm{t}}=\text { Harga pasar negara } \mathrm{i}
\end{aligned}
$$

Berdasarkan hasil pengolahan model AIDS, kemudian akan ditentukan nilai elastisitas-elastisitas untuk Indonesia dan negara pengekspor lainnya, yaitu: (1) elastisitas harga sendiri, (2) elastisitas silang dan (3) elastisitas pengeluaran dunia 
atas impor kakao olahan yang akan dihitung dengan menggunakan rumus berikut:

Elastisitas harga

$$
\eta_{t}=-1+\frac{\gamma_{i}}{S_{i}}+S_{i}
$$

Elastisitas silang

$$
\eta_{i j}=\frac{\gamma_{i j}}{S_{i}}+S_{j}
$$

Elastisitas pengeluaran

$$
\mu_{t}=1+\frac{\beta_{t}}{S_{t}}
$$

\section{HASIL DAN PEMBAHASAN}

\section{Analisis Revealed Comparative Advantage (RCA)}

Berdasarkan hasil perhitungan RCA pada kakao olahan Indonesia berupa kakao pasta, kakao butter, kakao bubuk dan cokelat dapat diketahui bahwa produk olahan kakao yang paling mempunyai daya saing adalah kakao butter dimana sejak tahun 1990 kakao butter Indonesia sudah memiliki daya saing dengan nilai RCA lebih besar dari satu dan terus meningkat ditahun-tahun berikutnya. Sementara produk yang tidak memiliki daya saing adalah cokelat

RCA Beberapa Negara Eksportir Utama Dunia

Kakao Pasta
Keunggulan komparatif tertinggi kakao pasta dimiliki oleh Pantai Gading (rata-rata RCA 276,86). Belanda $(4,94)$ dan Malaysia $(2,46)$ juga memiliki keunggulan komparatif yang lebih besar dari pada Indonesia $(1,79)$, padahal kedua negara ini bukan negara eksportir utama biji kakao. Malaysia yang banyak mengimpor biji kakao dari Indonesia memiliki daya saing yang lebih tinggi, artinya dengan memanfaatkan biji kakao Indonesia, industri hilir terutama olahan kakao berupa pasta di Malaysia lebih berkembang sehingga produknya memberikan nilai tambah yang lebih tinggi.

Belanda merupakan negara pengolah kakao utama dan menjadi pintu distribusi kakao pasta bagi negara-negara Eropa. Faktanya, Belanda merupakan negara importir utama biji kakao, yaitu sebesar 20,14 persen dari total impor dunia dan memiliki industri hilir kakao yang berkembang sehingga menjadi negara pengekspor kakao olahan yang berdaya saing. Jika dibandingkan dengan Jerman (rata-rata RCA 1,09) yang merupakan negara pengekspor kakao pasta terbesar ketiga dunia, Indonesia memiliki keunggulan komparatif yang lebih baik. Sebelum tahun 2010 Jerman tidak memiliki keunggulan komparatif, setelah tahun itu baru Jerman memiliki keunggulan komparatif lebih besar dari satu. Hal yang menarik untuk diungkapkan bahwa di tahun 2012, daya saing Indonesia untuk komoditas kakao pasta sudah melebihi Belanda dan Malaysia, dimana nilai RCA Indonesia mencapai 6.07 sementara Belanda sebesar 5.16 dan Malaysia 3.82 


\section{Kakao Butter}

Kakao Butter merupakan produk kakao Indonesia yang diekspor terbesar kedua setelah biji. Dilihat dari nilai RCA, keunggulan komparatif Indonesia (rata-rata RCA 5,48) sangat baik dan berada diatas Perancis (2,02). Namun apabila dibandingkan dengan Belanda (rata-rata RCA 9,27) dan Malaysia (7,09), daya saing kakao butter Indonesia masih dibawah dua negara tersebut. Hal ini mengindikasikan bahwa industri hilir kakao Belanda dan Malaysia sudah berkembang. Belanda merupakan negara yang memiliki industri grinding terbesar di dunia dan menguasai sepertiga grinding di Eropa.
Malaysia pada tahun 2002 mengalami peningkatan nilai RCA, namun ditahun 2011 dan 2012 sedikit mengalami penurunan. Hal ini disebabkan adanya penetapan bea keluar ekspor biji kakao Indonesia yang menyebabkan menurunnya impor biji kakao total Malaysia (sebelumnya sebagian besar ekspor kakao Indonesia ditujukan ke Malaysia). Menurut data dari UN Comtrade pada tahun 2011 terjadi penurunan impor biji kakao Malaysia sekitar 31 persen dan kembali turun sebesar 35 persen ditahun 2012. Bea keluar biji kakao Indonesia secara tidak langsung menyebabkan penurunan input bagi industri hilir kakao Malaysia.

\begin{tabular}{|c|c|c|c|c|c|c|c|c|c|c|}
\hline \multirow[t]{2}{*}{ Elastisitas } & \multicolumn{10}{|c|}{ Pangsa Pasar (Share) Negara } \\
\hline & Belanda & & $\begin{array}{l}\text { Pantai } \\
\text { Gading }\end{array}$ & & Jerman & & Malaysia & & Indonesia & \\
\hline Harga Belanda & 0.653 & & -0.121 & & -1.435 & * & 1.610 & ${ }^{* *}$ & -1.645 & *** \\
\hline $\begin{array}{l}\text { Harga Pantai } \\
\text { Gading }\end{array}$ & -0.137 & & -0.360 & & -0.346 & & -0.662 & & -0.353 & \\
\hline Harga Jerman & -1.007 & * & -0.214 & & 2.903 & & -1.749 & ** & 1.750 & $* *$ \\
\hline Harga Malaysia & 0.320 & $* *$ & -0.112 & & -0.496 & ** & -0.478 & & -0.101 & \\
\hline Harga Indonesia & -0.169 & & -0.032 & & 0.256 & $* *$ & -0.052 & & -0.310 & \\
\hline Pengeluaran & 1.518 & $* * *$ & 1.483 & ${ }^{* * *}$ & 1.302 & $* * *$ & 1.461 & $* * *$ & 2.703 & ${ }^{* * *}$ \\
\hline
\end{tabular}




\begin{tabular}{|c|c|c|c|c|c|c|c|c|c|}
\hline \multirow[t]{2}{*}{ Elastisitas } & \multicolumn{9}{|c|}{ Pangsa Pasar (Share) Negara } \\
\hline & Belanda & & Malaysia & & Perancis & Indonesia & & $\begin{array}{l}\text { Pantai } \\
\text { Gading }\end{array}$ & \\
\hline Harga Belanda & -0.182 & & 0.355 & & -0.660 & -1.351 & * & -1.265 & ** \\
\hline Harga Malaysia & 0.107 & & -0.890 & ** & 0.309 & 0.991 & ** & -0.848 & ** \\
\hline Harga Perancis & -0.177 & & 0.277 & & 0.395 & 0.476 & & 0.134 & \\
\hline Harga Indonesia & -0.211 & $*$ & 0.388 & & 0.277 & -0.698 & & 0.664 & ** \\
\hline $\begin{array}{l}\text { Harga Pantai } \\
\text { Gading }\end{array}$ & -0.248 & ** & -0.554 & ** & 0.098 & 0.835 & ** & 0.596 & \\
\hline Pengeluaran & 0.915 & *** & 0.971 & $* * *$ & 1.817 & 1.881 & *** & 1.692 & $* * *$ \\
\hline
\end{tabular}

\begin{tabular}{|c|c|c|c|c|c|c|c|c|c|c|}
\hline \multirow[t]{2}{*}{ Elastisitas } & \multicolumn{10}{|c|}{ Pangsa Pasar (Share) Negara } \\
\hline & Belanda & & Malaysia & & Jerman & & Spanyol & & Indonesia & \\
\hline Harga Belanda & -0.283 & & 0.219 & & 0.231 & & -0.145 & & -0.119 & \\
\hline $\begin{array}{l}\text { Harga } \\
\text { Malaysia }\end{array}$ & 0.037 & & -0.559 & & 0.267 & & 0.713 & $* *$ & -0.624 & \\
\hline Harga Jerman & 0.045 & & 0.307 & & 1.068 & & 0.690 & ** & -0.023 & \\
\hline Harga Spanyol & -0.015 & & 0.205 & & 0.355 & $* *$ & -1.427 & $* * *$ & 0.785 & $* *$ \\
\hline $\begin{array}{l}\text { Harga } \\
\text { Indonesia }\end{array}$ & -0.007 & & -0.215 & & -0.007 & & 0.457 & & 0.157 & \\
\hline Pengeluaran & 0.852 & $* * *$ & 1.783 & $* * *$ & 1.135 & $* * *$ & 1.609 & $* * *$ & 1.610 & $* * *$ \\
\hline
\end{tabular}

Pantai gading (rata-rata RCA 91,67) yang merupakan eksportir kakao butter keempat di dunia memiliki keunggulan komparatif tertinggi diantara negara eksportir utama lainnya. Sementara itu, walaupun Perancis merupakan negara eksportir kakao butter ketiga, namun memiliki daya saing yang paling rendah dibandingkan negara eksportir utama lainnya (rata-rata RCA 2,02). Hal ini disebabkan pangsa ekspor kakao pasta 
Perancis terhadap total ekspor seluruh komoditas Perancis sangat rendah.

\section{Kakao Bubuk}

Belanda merupakan negara yang memiliki keunggulan komparatif tertinggi untuk komoditas kakao bubuk dibandingkan negara lainnya (rata-rata RCA 11,49). Namun ditahun 2011 dan 2012, daya saing Malaysia lebih tinggi dibandingkan dengan Belanda. Malaysia memiliki nilai RCA yang tinggi sesuai dengan fakta bahwa kakao bubuk Malaysia memberi sumbangan produk kakao terbesar yang diekspor, diikuti butter dan pasta. Malaysia sudah tidak banyak mengekspor biji kakao lagi karena lahan perkebunan kakao bersaing dengan kelapa sawit.

Kakao bubuk Indonesia memiliki keunggulan komparatif yang cukup baik (rata-rata RCA 2,64). Walaupun Indonesia menempati urutan kelima dalam negara pengekspor kakao bubuk utama dunia, namun ditahun 2012, nilai RCA Indonesia menempati urutan ketiga dibanding negara lainnya. Jerman (rata-rata RCA 0,74) sebagai negara eksportir utama ketiga, sejak tahun 1993 tidak memiliki daya saing, hal ini ditunjukkan dengan nilai RCA dibawah satu. Ditahun 2010, produk kakao bubuk Jerman baru memiliki daya saing

\section{Cokelat}

Berdasarkan data tahun $1990 \quad-2012$, Indonesia belum memiliki daya saing untuk komoditas cokelat. Hal ini ditunjukkan dengan nilai RCA yang kurang dari satu.
Hal ini disebabkan industri pengolahan Indonesia sebagian besar mengolah biji kakao sampai pada tingkat setengah jadi (semi finished products) yakni produkproduk seperti kakao pasta, kakao butter dan kakao bubuk. Produk-produk tersebut sebagian besar dipasarkan ke luar negeri. Hanya sebagian kecil industri yang mengolah menjadi produk jadi (finished products) dan umumnya dipasarkan di dalam negeri. Eksportir cokelat masih didominasi negara-negara Eropa. Negara eksportir utama cokelat ditahun 2012 adalah Jerman, Belgia, Belanda, Perancis dan Amerika. Sementara ditahun itu Indonesia berada pada urutan ke 36. Negara yang memiliki daya saing paling tinggi adalah Belgia (rata-rata RCA 4,02) kemudian Belanda (2,37) setelah itu Jerman $(1,66)$ dan Perancis $(1,89)$.

\section{Analisis Indeks Spesialisasi Perdagangan (ISP)}

Untuk komoditas kakao bubuk indeks spesialisasi perdagangan yang dimiliki Indonesia berada pada tahap perluasan ekspor. Indeks Spesialisasi Perdagangan yang paling bagus dimiliki Indonesia untuk komoditas kakao butter dimana berkisar antara 0.99 dan 1. Hal ini berarti bahwa komoditas kakao butter Indonesia sejak tahun 1990 sampai 2012 (selama 22 tahun) sudah berada pada tahap kematangan. Komoditas yang memiliki indeks spesialisasi perdagangan paling buruk adalah cokelat. Berdasarkan nilai ISP, dapat diketahui bahwa cokelat Indonesia baru berada pada tahap perluasan ekspor. Bahkan ditahun 2004-2008, cokelat 
Indonesia berada pada tahap substitusi impor. Ini ditunjukkan dengan nilai ISP yang berkisar antara $-0,5$ dan 0 .

\section{Indeks Spesialisasi Perdagangan Beberapa Negara Eksportir Utama Dunia}

\section{Kakao Pasta}

Belanda sebagai negara pengekspor peringkat pertama ternyata memiliki nilai ISP dibawah 0,5. Hal ini berarti Belanda berada pada tahap pertumbuhan ekspor.Selain melakukan ekspor, Belanda juga masih mengimpor kakao pasta. Pantai Gading merupakan net eksportir kakao pasta. Hal ini ditunjukkan dengan nilai ISP sebesar satu. Nilai ISP Malaysia lebih baik dari Indonesia dimana sejak tahun 19902011 berkisar antara 0,9 dan 1. Namun ditahun 2012 terjadi penurunan, nilai ISP Malaysia menjadi 0,8. Hal ini terjadi karena persentase impor dibandingkan ekspor meningkat menjadi 44 persen dan ini merupakan prestasi Malaysia terburuk sepanjang 23 tahun terakhir. Jerman sebagai negara eksportir kakao pasta terbesar kedua dunia di tahun 2012 ternyata memiliki nilai ISP dibawah nol sejak tahun 2000. Hal ini disebabkan nilai impornya lebih besar dari ekspornya. Negara ini mere-ekspor kakao pasta yang diimpornya.

\section{Kakao Butter}

Indonesia merupakan net eksportir kakao butter dengan nilai ISP sebesar satu sepanjang 1990-2012. Hal yang sama juga terjadi pada Pantai Gading. Malaysia juga memiliki nilai ISP berkisar di angka satu, hanya saja ditahun 2011 dan 2012 nilai ini turun menjadi 0,9. Tahun 2011 nilai ekspor kakao butter Malaysia mengalami penurunan dari 614.675.440 US\$ menjadi 447.629.103 US\$, sementara nilai impornya mengalami peningkatan yang semula 5.136.363 US\$ di tahun 2010 menjadi 16.694.196 US\$ ditahun 2011. Perancis memiliki ISP yang paling rendah diantara lima negara pengekspor utama kakao butter, padahal negara ini menempati peringkat kedua eksportir utama dunia setelah Belanda di tahun 1998-2003 dan peringkat ketiga dunia di tahun 2004 -2012. Hal ini disebabkan negara ini mere-ekspor kakao butter yang diimpornya.

\section{Kakao Bubuk}

Malaysia memiliki nilai ISP berkisar antara 1 dan 0,9 sepanjang tahun 1990-2009. Ini menunjukkan kakao butter Malaysia berada pada tahap matang. Namun ditahun 2010 indeks ini turun menjadi 0,7 ditahun 2011 dan 2012. Jerman memiliki nilai ISP negatif dan berada pada tahap substitusi impor sejak 1993-2009, namun ditahun 2010 sudah berada pada tahap pertumbuhan ekspor. Belanda sebagai negara dengan nilai ekspor kakao bubuk tertinggi didunia sejak 1995 memiliki indeks ISP yang masih lebih rendah dibandingkan dengan Malaysia dengan rata-rata sebesar 0.8 sedangkan Malaysia 0.9 berdasarkan indeks tersebut menunjukkan keduanya berada pada tahap matang.

\section{Cokelat}


Tiga negara pengekspor utama cokelat dunia berada pada tahap pertumbuhan ekspor. Jerman sebagai negara pengekspor utama cokelat sepanjang tahun 1991-2012 memiliki nilai ISP berkisar antara 0,0-0,4. Berdasarkan data yang ada, Belgia memiliki nilai ISP yang tetap yaitu pada nilai 0,6. Sedangkan Belanda berada pada kisaran 0,2-0,5. Perancis sejak tahun 1998 -2012 berada pada tahap substitusi impor dengan nilai ISP -0,1. Indonesia memiliki nilai ISP yang lebih baik dari pada Perancis ditahun 2012. Padahal saat itu posisi Indonesia berada pada peringkat 36 eksportir cokelat dunia sedangkan Perancis berada pada peringkat keempat.

\section{Posisi Persaingan Kakao Olahan Indonesia dengan Negara Eksportir Lainnya}

Analisis mengenai posisi persaingan kakao olahan Indonesia dengan negara eksportir lainnya dilakukan dengan menggunakan model Almost Ideal Demand System (AIDS). Analisis dilakukan pada komoditas kakao pasta, kakao butter dan kakao bubuk. Komoditas cokelat tidak dianalisis disebabkan karena pada analisis sebelumnya, diketahui bahwa cokelat Indonesia tidak memiliki daya saing.

\section{Kakao Pasta}

Negara pengekspor utama kakao pasta dunia berturut-turut adalah Belanda, Pantai Gading, Jerman, Malaysia dan Indonesia. Hasil perhitungan elastisitas model AIDS dengan menggunakan Seemingly Unrelated Regression (SUR) untuk kelima negara tersebut ditunjukkan pada Tabel 1. Pada model AIDS, perhitungan elastisitas harga menunjukkan bahwa pangsa pasar kakao

pasta Indonesia tidak secara signifikan dipengaruhi oleh harga Indonesia. Hal ini juga terjadi pada komoditas kakao pasta Belanda, Pantai Gading, Malaysia dan Jerman terhadap harga sendiri. Sedangkan perhitungan elastisitas silang menunjukkan bahwa kakao pasta Indonesia memiliki hubungan komplementer dengan Belanda (nyata pada taraf $1 \%$ ) yang ditunjukkan dengan nilai negatif pada elastisitas silang $(-1,645)$. Ini berarti pangsa pasar kakao pasta Indonesia responsif terhadap perubahan harga kakao pasta Belanda.

Kakao pasta Indonesia memiliki hubungan substitusi dengan Jerman. Nilai elastisitas silang sebesar 1,75 menunjukkan bahwa pangsa pasar (share) Indonesia bersifat peka terhadap perubahan harga Jerman. Bila dilihat dari persamaan Jerman, dapat diketahui bahwa kakao pasta Jerman juga bersubstitusi dengan Indonesia. Namun nilai elastisitas silang Jerman sebesar 0,256 menunjukkan bahwa pangsa pasar Jerman tidak peka terhadap perubahan harga Indonesia. Jadi pangsa pasar Indonesia sangat responsif terhadap harga kakao Jerman, namun tidak sebaliknya.

Nilai elastisitas pengeluaran Indonesia adalah sebesar 2,703 sedangkan Belanda $(1,518)$, Pantai Gading (1,483), Malaysia $(1,461)$ dan Jerman $(1,302)$. Angka yang positif berarti bahwa peningkatan pengeluaran atas impor kakao pasta dunia akan meningkatkan pangsa pasar pada kelima negara pengekspor. Nilai elastisitas tertinggi yang dimiliki Indonesia berarti bahwa peningkatan permintaan dunia pada 
komoditas pasta kakao akan memberikan keuntungan yang paling besar bagi Indonesia dibandingkan negara ekportir pasta kakao lainnya.

\section{Kakao Butter}

Negara pengekspor utama kakao butter dunia berturut-turut adalah Belanda, Pantai Gading, Malaysia, Perancis dan Indonesia. Hasil perhitungan elastisitas model AIDS untuk kelima negara tersebut ditunjukkan pada Tabel 2. Kakao butter Indonesia memiliki hubungan saling berkomplementer dengan Belanda. Nilai elastisitas silang persamaan Indonesia dengan harga Belanda menunjukkan angka $-1,351$ (tanda negatif) nyata pada taraf 10 persen. Hal ini berarti pangsa pasar kakao butter Indonesia peka terhadap perubahan harga kakao butter Belanda. Pada persamaan Belanda terhadap harga Indonesia diperoleh angka elastisitas silang sebesar -0,211. Ini berarti pangsa pasar kakao pasta Belanda tidak responsif/tidak peka terhadap perubahan harga kakao butter Indonesia. Elastisitas pengeluaran menunjukkan bahwa Indonesia memiliki nilai tertinggi. Nilai elastisitas pengeluaran Indonesia adalah sebesar 1,881 sedangkan Perancis $(1,817)$, Pantai Gading $(1,692)$, Malaysia $(0,971)$ dan Belanda $(0,915)$

\section{Kakao Bubuk}

Negara pengekspor utama kakao bubuk dunia berturut-turut adalah Belanda,

Malaysia, Jerman, Spanyol dan Indonesia. Hasil perhitungan elastisitas model AIDS untuk kelima negara tersebut ditunjukkan pada Tabel 3. Berdasarkan tabel tersebut dapat dilihat bahwa pangsa pasar kakao butter Indonesia tidak peka terhadap perubahan harga kakao pasta negara lainnya. Begitu pula dengan negara eksportir kakao bubuk lainnya, perubahan harga di negara lain tidak peka terhadap perubahan harga kakao bubuk disuatu negara. Elastisitas pengeluaran menunjukkan bahwa peningkatan permintaan kakao bubuk dunia akan meningkatkan lima negara eksportir utama kakao bubuk yang dianalisis. Apabila terjadi peningkatan pengeluaran sebesar satu persen, maka pangsa pasar lima negara tersebut akan meningkat Malaysia (1,783 persen), Indonesia (1,610 persen), Spanyol (1,609 persen), Jerman (1,135 persen) dan Belanda ( 0,852 persen).

\section{Implikasi Kebijakan}

Hasil-hasil analisis di pembahasan sebelumnya menjadi informasi yang sangat berharga dalam menetapkan implikasi kebijakan ekspor kakao olahan. Berdasarkan perhitungan RCA (Revealed Comparative Advantage) dan ISP (Indeks Spesialisasi Perdagangan) maka ekspor kakao olahan Indonesia dititikberatkan pada kakao pasta, kakao butter dan kakao bubuk, sedangkan cokelat belum memiliki daya saing di pasar dunia.

\section{Kakao Pasta}

Pasar kakao pasta dunia me kakao pasta Belanda dan Indonesia saling melengkapi (komplementer). Pengaruh harga kakao pasta Belanda terhadap pangsa pasar Indonesia sangat besar. Daya saing Belanda lebih besar dari Indonesia. Indeks Spesialisasi Perdagangan Belanda menunjukkan bahwa Belanda berada pada 
tahap pertumbuhan ekspor dimana impor kakao pasta Belanda masih cukup besar. Elastisitas silang antara Belanda dan Indonesia menunjukkan bahwa apabila harga kakao pasta Belanda turun, maka tidak hanya pangsa pasar Belanda yang meningkat, pangsa pasar Indonesia pun akan meningkat.

Strategi yang dilakukan adalah melakukan kerjasama dengan Belanda sehingga Indonesia dapat mengekspor kakao pasta langsung ke Belanda tanpa harus melalui Jerman. Jerman merupakan salah satu tujuan utama kakao pasta Indonesia. Pasta kakao yang diimpor Jerman akan diekspor kembali (re-ekspor) yang salah satu tujuan utamanya adalah ke Belanda. Dengan memutus rantai Belanda dan Jerman diharapkan harga kakao butter Belanda dapat turun.

Komoditas kakao pasta dari Indonesia dan Jerman saling bersubstitusi (menggantikan). Pengaruh harga kakao pasta Indonesia terhadap pangsa pasar (share) Jerman sangat kecil, sedangkan pengaruh harga kakao pasta Jerman terhadap share Indonesia sangat besar. Berdasarkan perhitungan nilai RCA, daya saing Indonesia jauh lebih tinggi dibandingkan dengan Jerman meskipun Jerman merupakan eksportir ketiga kakao pasta dunia. Sedangkan Indeks Spesialisasi Perdagangan Jerman menunjukkan bahwa impor kakao pasta Jerman masih tinggi. Ini membuktikan bahwa Jerman mereekspor kakao pasta yang diimpornya. Bagi Indonesia, jika harga kakao pasta Jerman lebih kompetitif (lebih murah), maka pangsa pasar kakao pasta Indonesia akan turun.

Strategi yang dilakukan adalah Indonesia harus meningkatkan kualitas kakao pastanya sehingga dapat diterima di negara tujuan ekspor Jerman, terutama Belanda. Dengan demikian pasokan kakao pasta yang diimpor ke Jerman akan berkurang dan harga kakao pasta Jerman akan meningkat.

\section{Kakao Butter}

Pasar kakao butter dunia memandang bahwa kakao butter Indonesia dan Belanda saling melengkapi (komplementer). Pengaruh harga kakao butter Belanda terhadap pangsa pasar Indonesia lebih besar dari pada pengaruh harga kakao butter Indonesia terhadap Belanda. Daya saing kakao butter Belanda lebih besar dari Indonesia. Indeks Spesialisasi Perdagangan Belanda menunjukkan bahwa Belanda berada pada tahap pertumbuhan ekspor dimana impor kakao pasta Belanda masih cukup besar. Elastisitas silang antara Belanda dan Indonesia menunjukkan bahwa apabila harga kakao butter Belanda turun, maka tidak hanya pangsa pasar Belanda yang meningkat, pangsa pasar Indonesia pun akan meningkat.

Strategi yang dilakukan menjalin kerjasama dengan Belanda agar Indonesia dapat mengekspor kakao butter langsung ke Belanda. Salah satu negara pengimpor kakao butter ke Belanda adalah Malaysia. Malaysia memang tidak melakukan impor kakao butter dari Indonesia, namun mengimpor biji kakao. Idris et.all (2009) 
mengemukakan bahwa Malaysia mendapatkan banyak nilai tambah dari mengimpor biji kakao dengan jumlah yang banyak terutama dari Indonesia, mengolahnya lalu mengekspor kakao olahan tersebut ke negara lain. Dengan diberlakukannya bea keluar biji kakao maka ekspor kakao butter Malaysia berkurang. Indonesia dapat menggunakan kesempatan ini dengan melakukan kerjasama dengan Belanda sehingga Belanda mengimpor kakao pasta langsung dari Indonesia. Dengan memutus rantai Belanda dan Malaysia diharapkan harga kakao butter Belanda dapat turun.

\section{KESIMPULAN DAN SARAN}

\section{Kesimpulan}

1. Indonesia memiliki daya saing yang tinggi untuk komoditas kakao pasta (rata-rata nilai RCA 1,79), kakao butter (rata-rata RCA 5,48) dan kakao bubuk (rata-rata RCA 2,46), sedangkan cokelat Indonesia belum memiliki daya saing (rata-rata RCA 0,23).

2. Daya saing kakao pasta Indonesia berada dibawah Pantai Gading (ratarata nilai RCA 276,86), Belanda $(4,94)$ dan Malaysia $(2,46)$, namun lebih tinggi dari Jerman $(1,09)$. Kakao butter Indonesia memiliki daya saing diatas Perancis (2,02), namun masih dibawah Pantai Gading $(91,67)$, Belanda $(9,27)$ dan Malaysia $(7,09)$. Sedangkan kakao bubuk Indonesia memiliki daya saing dibawah Belanda $(11,49)$ dan Malaysia $(5,18)$, namun lebih baik dibandingkan Spanyol $(2,26)$ dan Jerman $(0,74)$.
3. Daya saing kakao olahan Indonesia berdasarkan Indeks Spesialisasi Perdagangan diketahui bahwa: a) Pantai gading merupakan net eksportir kakao pasta, Malaysia berada pada tahap matang sama dengan Indonesia, Belanda berada pada tahap perluasan ekspor dan Jerman berada pada tahap substitusi impor, b) Indonesia dan Pantai Gading merupakan net eksportir kakao butter diikuti Malaysia yang berada pada tahap matang, Belanda dan Perancis pada tahap perluasan ekspor c) Kakao bubuk Belanda, Malaysia, Spanyol, Indonesia dan Jerman berada pada tahap perluasan ekspor.

4. Pasar dunia memandang bahwa kakao pasta Belanda dan Indonesia saling melengkapi sementara kakao pasta Jerman dan Indonesia saling bersubstitusi. Sedangkan kakao butter Indonesia dan Belanda saling berkomplementer.

\section{Saran}

1. Indonesia sebaiknya menjalin kerjasama dengan Belanda untuk komoditas kakao pasta dan kakao butter karena pada komoditas ini Indonesia dan Belanda saling berkomplementer.

2. Indonesia perlu meningkatkan kualitas kakao pasta dan kakao bubuknya agar bernilai lebih tinggi dengan memperhatikan standar kualitas yang ada dipasar Belanda agar dapat bersaing dengan Jerman (untuk 
komoditas kakao pasta) dan Malaysia (untuk komoditas kakao butter).

3. Indonesia tetap memberlakukan bea keluar biji kakao. Hal ini dilakukan agar biji kakao yang selama ini sebagian besar diekspor dapat diolah sendiri sehingga mendapatkan nilai tambah

\section{DAFTAR PUSTAKA}

Balassa dan Bela. 1965. Trade Liberalization and Revealed Comparative Advantage, Manchester School of Economics and Statistics, vol 33. Juni . p 99124.

Deaton and Muellbauer. 1980. An Almost Ideal Demand System. American Economic Review, Vol. 70, Sep. p 312-325.

Honma, M. 1993. Growth in Horticultural Trade: Japan's Market for Developing Countries. Agricultural Economics, Vol 9. 37-51.

Idris, N, Amna Awad, M Azaly N dan Fatimeh M. 2009. Export Performance and Trade Competitiveness of Malaysian Cocoa Products. Institute Agriculture and Food Policy
Studies, Universiti Putra Malaysia.

ICCO (International Cocoa Organization). 2013. Quarterly Bulletin of Cocoa Statistics, Volume XXXVIII No.4, Cocoa Year 2012/2013.

http://www.icco.org/aboutus/international-cocoaagreements/cat_view/30-relateddocuments/46-statisticsproduction.html.

ICCO (International Cocoa Organization). 2012. The World Cocoa Economy: Past and Present. http://www.icco.org/aboutus/inte rnational-cocoaagreements/cat_view/30-relateddocuments/45-statistics-otherstatistics.html.

United Nations. Commodity Trade Statistics Database (COMTRADE). http://comtrade.un.org/db/dqQiu ckQuery.aspx.

Winter, A. 1984. Separability and Specification of Foreign Trade Function. Journal of International Economics, vol. 17, Sept. p 239-263.

* Alumni Program Studi Magister Agribisnis dan ** Dosen Fakultas Sains dan Teknologi UIN Syarif Hidayatullah Jakarta 